\title{
Growth Promoter Effect of Ginger, Garlic and Fenugreek on Pacific White Leg Shrimp (Litopenaeus vannamei)
}

\author{
R. Mahesh Kumar, A. Chandra Sekhara Rao, Narshivudu Daggula*, \\ Ganesh Guguloth, B. Yesu Das and Ashok Indhuri
}

College of Fishery Science, Muthukuru, Andhra Pradesh, India

*Corresponding author

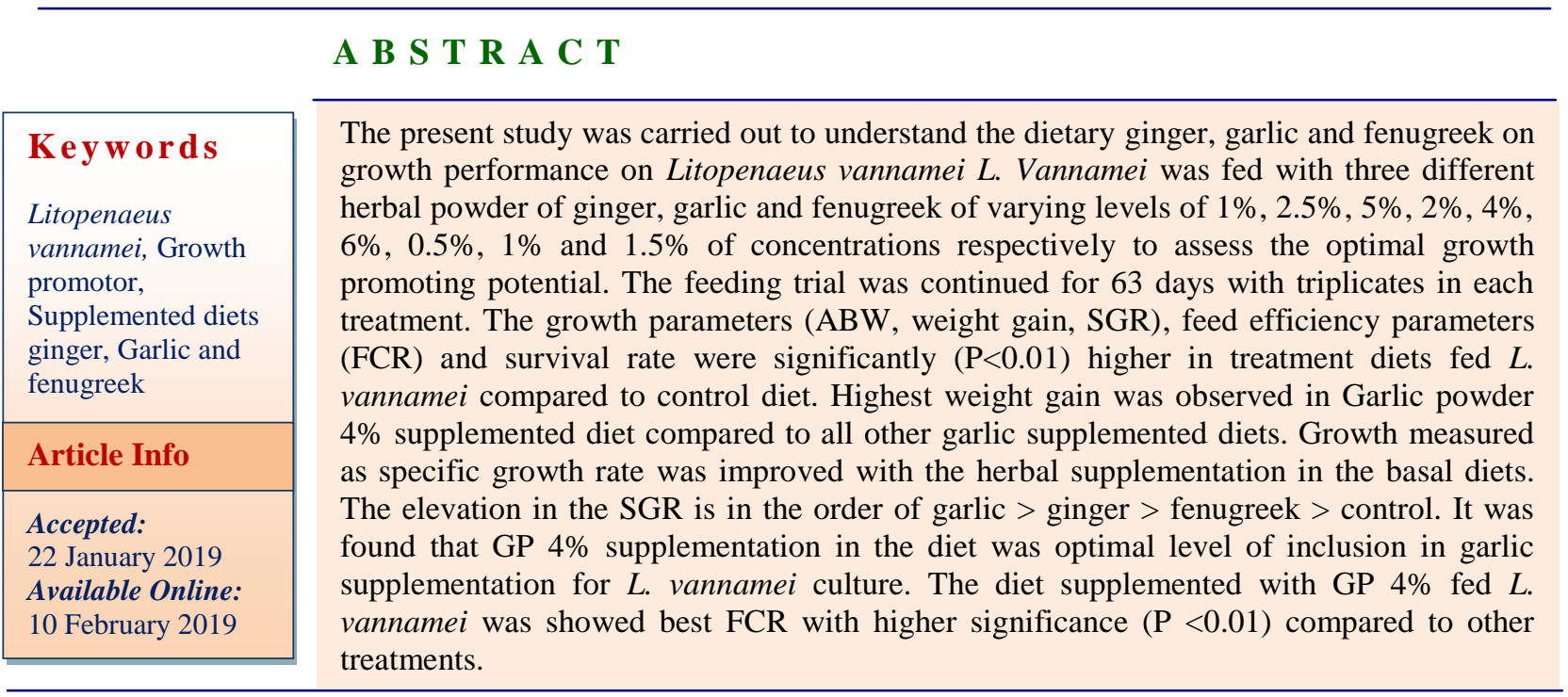

\section{Introduction}

Globally aquaculture production has become the rapid growing food production sector. It provides high-quality animal protein with total global production increasing from 63.6 million tonnes in 2011 to 66.63 million tonnes in 2012 (FAO). For high production people are started to incorporate antibiotic growth promoters in feed. But due to its negative impacts (residual accumulation in fish tissue, emergence of antibiotic resistant microbes) natural compounds are more acceptable to the public. The herbal immunostimulants which have been reported to enhance efficiency of feed utilization and animal productive performance (Levis et al., 2008). The herbal plants have a wide variety of properties such as: antioxidant, antimicrobial, anticarcinogenic, analgesic, insecticidal, antiparasitic, anticoccidial, growth promoters, appetite enhancement, stimulant of secretion of bile and digestive enzyme activity, laxatives and antidiarrhea, hepatoprotection (Coutteau et al., 2011). 
Garlic, Allium sativum L., has been used for the treatment of many diseases since ancient times as reported in the Codex Ebers (1550 BC) where an Egyptian medical papyrus described several therapeutic formulas based on the garlic as a useful remedy for a variety of diseases such as heart problems, headache, bites, worms and tumors. Garlic (Allium sativum) has several beneficial effects for human and animals, exhibiting antimicrobial, antioxidant, and antihypertensive properties Sivam (2001). Garlic can help in the control of pathogens, especially bacteria and fungi, and increase the welfare of fish (Corzo, 2007).

Ginger (Zingiber officinalis) belongs to Zingiberaceae family. The part of the plant used is the rhizome, an important spice. The use of spices as food and feed additives has been practiced widely since ancient times. Till date, no study has been carried out on the shrimp with $Z$. officinalis as an herbal appetizer. Therefore, in the present study, $Z$. officinalis was chosen and the stimulatory effect verified. Various percentages of $Z$. officinalis was prepared and fed to postlarvae (PL-1-30) of Penaeus monodon through the live feed Artemia franciscana, because of its versatile characteristics, such as taste, high nutritive value, non selecting filter-feeding capability and non-contamination of the culture water. Ginger increases the pancreatic and intestine lipase (Platel and Srinivasan, 2000).

Fenugreek (Trigonella foenumgraecum) is an annual herb that belongs to the family Leguminosae widely grown in Pakistan, India, Egypt, and Middle Eastern countries (Alarcon-Aguilara et al., 1998). Fenugreek has also been reported to exhibit pharmacological properties such as antitumor, antiviral, antimicrobial, anti-inflammatory, hypotensive and antioxidant activity (Cowan et al., 1999 and Shetty et al., 1997).

\section{Materials and Methods}

Litopenaeus vannamei (1000 numbers) were obtained from CP Hatchery, Nellore. Shrimp seed were packed in double plastic bags filled with oxygen and water in the ratio of 3:1 in each bag and the density of shrimp was 300/bag. Post larvae (PL10) transported by road in plastic bags containing $15 \mathrm{ppt}$ saline water. PL transferred to the same salinity water in cement tanks of the wet lab. Acclimatization was carried out over 10 days. During this period the seed were fed apparent satiation with control diet. The number of shrimp seed to be packed in oxygen inflated polythene bags was calculated as per the following formula (Jameson et al., 1995). $\mathrm{N}=$ (DO - 2) X V/CH Where: DO: Dissolved oxygen content of water $(\mathrm{mg} / \mathrm{l}), \mathrm{V}$ : Volume of water used for transport (Lt), C: Rate of oxygen consumption of shrimp $(\mathrm{ml} / \mathrm{kg}$ of shrimp), H: Duration of transport (Hours)

\section{Experimental design}

The aquarium tanks used for experiments were of size $60 \times 30 \times 30 \mathrm{~cm}$ (Plate 3). Thirty aquariums including control were stalked on iron racks. Aquariums were located in a secured place where there is no direct sunlight and covered all the sides with black paper to avoid algal growth in the tank. Water in the aquariums was aerated by using air stones connected to the air compressor. Filters are used for filtering the aquarium water. The underground water was taken into a tank and allowed to aerate for 48 hours and was used for filling the aquaria. Salinity was checked before taking the water into aquarium. The water is allowed to pass through biofilter filter for 24 hours before introducing the shrimps into the aquaria. In each aquarium 12 numbers of shrimps with initial average weights of $3.2 \pm 0.11 \mathrm{gm}$ were introduced and triplicates were maintained for each treatment. Regular water exchange of $25 \%$ 
was done every day. Left over feed, excreta and other debris was siphoned off from the bottom of the tank without disturbing the shrimps at every 2 hours.

\section{Experimental feed preparation and feeding}

Garlic, ginger and fenugreeks were purchased in sufficient quantities from local market. The ingredients were sun dried for 2 weeks and powdered at required quantities before feed preparation. Ten experimental diets (Plate 8) were prepared by supplementing a basal formulated diet with different levels $0 \%$ (Control), 2\%, 4\%, 6\%, 1\%, 2.5\%, 5\%, 0.5\%, $1 \%$ and $1.5 \%$ of garlic, ginger and fenugreek powders respectively. The growth parameters of all the shrimps of each aquarium were individually estimated by taking their total body length and weight at 7 days interval.

\section{Weight gain}

Weight increment was obtained by subtracting initial body weight from the final body weight. Weight gain $(\mathrm{gm})=$ Final body weight (gm) - Initial body weight (gm) .

\section{Specific growth rate}

Specific growth rate was calculated by the formula

$\left[\left(\mathrm{L}_{\mathrm{n}} \mathrm{FBW}-\mathrm{L}_{\mathrm{n}} \mathrm{IBW}\right) /\right.$ day $] \times 100$

FBW -- Final body weight

IBW -- Initial body weight

Ln -- Logarithm

Day -- duration of experiment (63 days)

\section{Results and Discussion}

Growth of $L$. vannamei fed with garlic powder (GP) supplementation

Observations on the growth during the first week $\left(7^{\text {th }}\right.$ day) revealed that weight gain varied between $0.9 \pm 0.05 \mathrm{~g}$ and $1.25 \pm 0.12 \mathrm{~g}$ for treatment GP $2 \%$ and GP $4 \%$ respectively. Highest and lowest average weight values were observed in the treatments GP $4 \%$ $(4.45 \pm 0.04 \mathrm{~g})$ and GP $2 \%(4.1 \pm 0.11 \mathrm{~g})$. On the $14^{\text {th }}$ day highest weight gain of $1.22 \pm 0.07 \mathrm{~g}$ and lowest weight gain of $0.8 \pm 0.03 \mathrm{~g}$ were recorded for the GP $6 \%$ and control respectively. Highest average weight values $(5.57 \pm 0.12 \mathrm{~g})$ and lowest average weight values $(5.1 \pm 0.04 \mathrm{~g})$ were recorded for GP $4 \%$ and control respectively during the second sample $\left(14^{\text {th }}\right.$ day). On the $21^{\text {st }}$ day the highest and lowest weight gain observed were $0.92 \pm 0.06 \mathrm{~g}$ and $0.51 \pm 0.10 \mathrm{~g}$ for GP $4 \%$ and GP $6 \%$ respectively, while the highest and lowest average weight values observed were $(6.49 \pm 0.04 \mathrm{~g}$ and $5.67 \pm 0.02 \mathrm{~g})$ for GP $4 \%$ and GP $6 \%$ respectively. During the $28^{\text {th }}$ day, the highest and lowest weight gain observed were $1.25 \mathrm{~g} \pm 0.11 \mathrm{~g}$ and $0.95 \pm 0.11 \mathrm{~g}$ for GP $4 \%$ and GP 6\% respectively. The highest and lowest average weight values observed were $(7.74 \pm 0.01 \mathrm{~g}$ and $6.62 \pm 0.07 \mathrm{~g}$ ) for GP $4 \%$ and GP $6 \%$ respectively. On the $35^{\text {th }}$ day of the experiment Highest and lowest weight gain observed were $0.8 \pm 0.04 \mathrm{~g}$ and $0.2 \pm 0.01 \mathrm{~g}$ for GP $6 \%$ and GP 4\% respectively. The highest and lowest average weight values observed were $(7.94 \pm 0.05 \mathrm{~g}$ and $7.32 \pm 0.04 \mathrm{~g})$ for GP $4 \%$ and control respectively. GP 2\% and GP 6\% stood in second and third positions with weight of $7.85 \pm 0.01 \mathrm{~g}$ and $7.42 \pm 0.11 \mathrm{~g}$ respectively. On the $42^{\text {nd }}$ day highest weight gain of $1.15 \pm 0.07 \mathrm{~g}$ and lowest weight gain of $0.75 \pm 0.02 \mathrm{~g}$ were recorded for the GP $4 \%$ and GP 6\% respectively. Highest average weight values $9.09 \pm 0.08 \mathrm{~g}$ and lowest average weight values $8.17 \pm 0.07 \mathrm{~g}$ were recorded for GP $6 \%$ and control respectively (Fig. 1).

On the $49^{\text {th }}$ day highest weight gain of $0.75 \pm 0.01 \mathrm{~g}$ and lowest weight gain of $0.31 \pm 0.03 \mathrm{~g}$ were recorded for GP $4 \%$ and control respectively. Highest average weight values $9.84 \pm 0.07 \mathrm{~g}$ and lowest average weight 
values $8.48 \pm 0.03 \mathrm{~g}$ were recorded for GP $4 \%$ and control respectively. Highest average weight values of $11.97 \pm 0.07 \mathrm{~g}$ from GP $4 \%$ and lowest average weight values of $9.55 \pm 0.07 \mathrm{~g}$ from control were observed at the end of the experiment. An overall study indicated that the GP $4 \%$ recorded $\mathrm{ABW}$ of $11.97 \pm 0.07 \mathrm{~g}$ in the 63 days' experimental period. This was followed by the GP $2 \%$ $(10.68 \pm 0.04 \mathrm{~g}), \quad$ GP $\quad 6 \% \quad(9.70 \pm 0.05 \mathrm{~g})$ and control $(9.55 \pm 0.07 \mathrm{~g})$ they stood in second, third and fourth positions respectively.

The use of spices as dietary supplements has been practiced widely since time immemorial. Apart from enhancing the palatability of feed, herbal supplements have been widely believed to exert digestive stimulant action and growth promotion (venkataramalingam et al., 2007).

The weight gain attained in GP 4\% treatment diet fed L. vannamei was also significantly ( $\mathrm{P}$ $<0.01)$ higher compared to other treatment diets. Poongodi et al., (2012) were reported similar increase in weight gain of $M$. rosenbergii PL in the experimental diets over control. Similar results with garlic supplementation at 5\% concentration were obtained by Rebecca and Bhavan (2014) in M. rosenbergii. Labrador et al., (2016) were observed highest weight gain in L. vannamei fed with diet containing $6 \%$ garlic powder. The enhanced growth rate of the treatment groups may be attributed to the growth promoting substances present in the garlic powder. The growth data was subjected to analysis of variance (ANOVA) at $1 \%$ and 5\% level of significance. The statistical analysis has shown that $\mathrm{F}$ - value is found to be significant among treatments. Since F- value is found to be significant, the pair wise comparison of any two Treatments could be done by computing RBD two way classification. The Treatment GP $4 \%$ is found to be significantly superior when compare to other Treatments. Treatment GP 4\% has shown significantly different from all other Treatments. The second and third positions were occupied by GP $2 \%$ and GP $6 \%$ respectively. There was a significant difference between the culture periods also.

Highest weight gain in $L$. vannamei was noticed in the GP $4 \%$ herbal supplemented diets treatment compared to other treatments throughout experimental period performance related to progressive increase of garlic concentration was found to be significant $(\mathrm{P}$ $<0.01)$ among treatments. The growth promoting potential of several herbs on aquatic animals has been tested by many workers. The results were correlated with the observations in the present study (Chitrasu et al., 2002).

\section{Growth of $L$. vannamei fed with different concentrations of ginger powder supplementation}

Observations on the growth during the first week ( $7^{\text {th }}$ day) revealed that weight gain varied between $0.91 \pm 0.06 \mathrm{~g}$ and $1.24 \pm 0.11 \mathrm{~g}$ for treatment $\mathrm{ZP} \quad 1 \%$ and $\mathrm{ZP} \quad 2.5 \%$ respectively. Highest and lowest average weight values were observed in the treatments $\mathrm{ZP} \quad 2.5 \% \quad(4.44 \pm 0.05 \mathrm{~g})$ and $\mathrm{ZP} \quad 1 \%$ $(4.11 \pm 0.10 \mathrm{~g})$. On the $14^{\text {th }}$ day highest weight gain of $1.12 \pm 0.10 \mathrm{~g}$ and lowest weight gain of $0.7 \pm 0.07 \mathrm{~g}$ were recorded for the ZP $1 \%$ and ZP 5\% respectively. Highest average weight values $(5.48 \pm 0.07 \mathrm{~g})$ and lowest average weight values $(5.09 \pm 0.07 \mathrm{~g})$ were recorded for ZP $2.5 \%$ and ZP 5\% respectively during the second sample $\left(14^{\text {th }}\right.$ day). On the $21^{\text {st }}$ day The highest and lowest weight gain observed were $0.94 \pm 0.04 \mathrm{~g}$ and $0.42 \pm 0.02 \mathrm{~g}$ for $\mathrm{ZP} 2.5 \%$ and ZP $1 \%$ respectively, while the highest and lowest average weight values observed were $(6.42 \pm 0.10 \mathrm{~g}$ and $5.65 \pm 0.04 \mathrm{~g})$ for ZP $2.5 \%$ and ZP $1 \%$ respectively. During the $28^{\text {th }}$ day, the highest weight gain observed were 
$1.15 \pm 0.12 \mathrm{~g}$ in $\mathrm{ZP} 1 \%$ and control. The lowest weight gain observed were $0.65 \pm 0.01 \mathrm{~g}$ for $\mathrm{ZP}$ $2.5 \%$. The highest and lowest average weight values observed were $(7.07 \pm 0.05 \mathrm{~g}$ and $6.66 \pm 0.02 \mathrm{~g})$ for $\mathrm{ZP} 2.5 \%$ and $\mathrm{ZP}$ $5 \%$ respectively. On the $35^{\text {th }}$ day of the experiment Highest and lowest weight gain observed were $1.14 \pm 0.10 \mathrm{~g}$ and $0.41 \pm 0.04 \mathrm{~g}$ for ZP $1 \%$ and control respectively. The highest and lowest average weight values observed were $(8.02 \pm 0.02 \mathrm{~g}$ and $7.32 \pm 0.04 \mathrm{~g})$ for $\mathrm{ZP}$ $2.5 \% \%$ and control respectively. ZP $1 \%$ and ZP 5\% stood in second and third positions with weight gain of $7.9 \pm 0.02 \mathrm{~g}$ and $7.62 \pm 0.04 \mathrm{~g}$ respectively.

On the $42^{\text {nd }}$ day highest weight gain $0.91 \pm 0.10 \mathrm{~g}$ and lowest weight gain $0.35 \pm 0.01 \mathrm{~g}$ were recorded for the $\mathrm{ZP} 2.5 \%$ and ZP $1 \%$ respectively. Highest average weight values $8.93 \pm 0.04 \mathrm{~g}$ and lowest average weight values $8.17 \pm 0.07 \mathrm{~g}$ were recorded for ZP $2.5 \%$ and control respectively. On the $49^{\text {th }}$ day highest weight gain $0.9 \pm 0.08 \mathrm{~g}$ and lowest weight gain $0.22 \pm 0.03 \mathrm{~g}$ were recorded for $\mathrm{ZP}$ $2.5 \%$ and $\mathrm{ZP} 1 \%$ respectively. Highest average weight values $9.83 \pm 0.07 \mathrm{~g}$ and lowest average weight values $8.48 \pm 0.03$ were recorded for $\mathrm{ZP} 2.5 \%$ and control respectively. On the $56^{\text {th }}$ day highest weight gain $1.11 \pm 0.11 \mathrm{~g}$ and lowest weight gain of $0.82 \pm 0.06 \mathrm{~g}$ were recorded for $\mathrm{ZP} 2.5 \%$ and control respectively.

Highest average weight values $10.94 \pm 0.08 \mathrm{~g}$ and lowest average weight values $9.3 \pm 0.06 \mathrm{~g}$ were recorded for ZP 2.5\% and control respectively. Highest average weight values of $11.79 \pm 0.02 \mathrm{~g}$ from $\mathrm{ZP} 2.5 \%$ and lowest average weight values of $9.55 \pm 0.07 \mathrm{~g}$ from control were observed at the end of the experiment. An overall study indicated that the $\mathrm{ZP} 2.5 \%$ recorded ABW of $11.79 \pm 0.02 \mathrm{~g}$ in the 63 days experimental period. This was followed by the ZP 5\% (10.1 $\pm 0.08 \mathrm{~g})$, ZP $1 \%$ $(9.95 \pm 0.03 \mathrm{~g})$ and control $(9.55 \pm 0.07 \mathrm{~g})$ they stood in second, third and fourth positions respectively.

The statistical analysis has shown that Fvalue is found to be significant among treatments. Since F- value is found to be significant, the pair wise comparison of any two Treatments could be done by computing RBD two way classification. The Treatment ZP $2.5 \%$ is found to be significantly superior when compare to other Treatments. Treatment ZP 2.5\% has shown growth performance significantly different from all other Treatments. The second and third positions were occupied by ZP 5\% and ZP $1 \%$ respectively. There was a significant difference between the culture periods also. Ginger place very important role in fat digestion and adsorption (Platel and Srinivasan, 2000). In the present study growth performance through elevation in the average weight and weight gain were showed fluctuating trends with the progression of experimental period. Highest average weight $(11.79 \pm 0.02 \mathrm{~g})$ weight gain $(1.24 \pm 0.11 \mathrm{~g})$ were observed in $L$. vannamei fed with the $\mathrm{ZP}$ $2.5 \%$ supplemented diets among all treatments. Ginger supplemented diets were demonstrated better growth performance compared to control throughout experimental period (Figure 2). It was noticed that ZP 2.5\% supplemented diets performed highest significance $(P<0.01)$ in the elevation of growth in L. vannamei compared to all the treatments. The growth performance in $L$. vannamei fed with ginger supplemented diets may be attributed to the growth stimulants, enhanced digestive enzymes activity present in herbs and P. monodon post larvae when fed with pepain constituent of papaya leaf were showed increase in weight gain (Penaflorida, 1995). Kesavnath and Jayaram (2000) reported an improvement in the growth of $M$. rosenbergii with the supplementation of Nutripro-aqua, a soya based herbal product. Ginger (100\%) enriched artemia fed $P$. 
monodon PL was showed the highest weight gain $(130.8 \pm 1.7 \mathrm{mg})$ compared to non enriched artemia treatment $(74.8 \pm 2.0 \mathrm{mg})$ (Venkataramalingam et al., 2007). Rebecca and Bhavan (2014) were also reported Z.officinale improved feed intake and promoted the growth in the PL of $M$. rosenbergii. El-Desouky et al., (2012) were noticed similar results on the effect of Z.officinale on the growth of $M$. rosenbergii. (Chang et al., 2012) were observed similar weight gain increase with the consequential increase of zingerione in $L$. vannamei juveniles. Similar growth performance in aquatic organism with the inclusion of ginger in the feed was reported by earlier workers (Poongodi et al., 2012 and Rahimi et al., 2015).

\section{Growth of $L$. vannamei fed with different concentrations of fenugreek powder supplementation}

Observations on the growth during the first week $\left(7^{\text {th }}\right.$ day) revealed that weight gain varied between $1.18 \pm 0.12 \mathrm{~g}$ and $0.82 \pm 0.04 \mathrm{~g}$ for treatment FP $1 \%$ and FP $0.5 \%$ respectively. Highest and lowest average weight values were observed in the treatments FP $1 \% \quad(4.38 \pm 0.04 \mathrm{~g})$ and FP $0.5 \%$ $(4.02 \pm 0.07 \mathrm{~g})$. On the $14^{\text {th }}$ day highest weight gain of $1.35 \pm 0.12 \mathrm{~g}$ and lowest weight gain of $0.8 \pm 0.03 \mathrm{~g}$ were recorded for the FP $1.5 \%$ and control respectively. Highest average weight values $(5.6 \pm 0.02 \mathrm{~g})$ and lowest average weight values $(5.10 \pm 0.11 \mathrm{~g})$ were recorded for FP $1 \%$ and control respectively during the second sample $\left(14^{\text {th }}\right.$ day). On the $21^{\text {st }}$ day The highest and lowest weight gain observed were $1.1 \pm 0.10 \mathrm{~g}$ and $0.52 \pm 0.02 \mathrm{~g}$ for FP $1 \%$ and FP $0.5 \%$ respectively, while the highest and lowest average weight values observed were $(6.7 \pm 0.08 \mathrm{~g}$ and $5.76 \pm 0.05 \mathrm{~g})$ for FP $1 \%$ and control respectively. During the $28^{\text {th }}$ day, the highest and lowest weight gains observed were $1.15 \pm 0.12 \mathrm{~g}$ and $0.42 \pm 0.02 \mathrm{~g}$ for control and FP $1 \%$ respectively. The highest and lowest average weight values observed were $(7.12 \pm 0.01 \mathrm{~g}$ and $6.64 \pm 0.07 \mathrm{~g}$ ) for FP $1 \%$ and FP $0.5 \%$ respectively. On the $35^{\text {th }}$ day of the experiment Highest and lowest weight gain observed were $1.26 \pm 0.12 \mathrm{~g}$ and $0.41 \pm 0.04 \mathrm{~g}$ for FP $0.5 \%$ and control respectively. The highest and lowest average weight values observed were $(8.2 \pm 0.04 \mathrm{~g}$ and $7.32 \pm 0.04 \mathrm{~g})$ for FP $1 \%$ and FP $0.5 \%$ respectively (Fig. 3).

On the $42^{\text {nd }}$ day highest weight gain $0.85 \pm 0.01 \mathrm{~g}$ and lowest weight gain $0.45 \pm 0.01 \mathrm{~g}$ were recorded for the control and FP $1.5 \%$ respectively. Highest average weight values $8.85 \pm 0.07 \mathrm{~g}$ and lowest average weight values $8.16 \pm 0.05 \mathrm{~g}$ were recorded for FP $1 \%$ and FP $1.5 \%$ respectively. On the $49^{\text {th }}$ day highest weight gain $1.13 \pm 0.14 \mathrm{~g}$ and lowest weight gain of $0.31 \pm 0.03 \mathrm{~g}$ were recorded for FP $1 \%$ and control respectively.

Highest average weight values $9.98 \pm 0.12 \mathrm{~g}$ and lowest average weight values $8.48 \pm 0.03 \mathrm{~g}$ were recorded for FP $1 \%$ and control respectively. On the $56^{\text {th }}$ day highest weight gain $0.92 \pm 0.10 \mathrm{~g}$ and lowest weight gain of $0.75 \pm 0.12 \mathrm{~g}$ were recorded for FP $1.5 \%$ and FP $0.5 \%$ respectively. Highest average weight values $10.86 \pm 0.02 \mathrm{~g}$ and lowest average weight values $9.3 \pm 0.06 \mathrm{~g}$ were recorded for FP $1 \%$ and control respectively. Highest average weight values of $11.35 \pm 0.03 \mathrm{~g}$ from FP $1 \%$ and lowest average weight values of $9.55 \pm 0.07 \mathrm{~g}$ from control were observed at the end of the experiment. An overall study indicated that the FP $1 \%$ recorded $\mathrm{ABW}$ of $11.35 \pm 0.03 \mathrm{~g}$ in the 63 days experimental period. This was followed by the FP $1.5 \%$ $(11.07 \pm 0.08 \mathrm{~g})$, FP $0.5 \%(10.05 \pm 0.02 \mathrm{~g})$ and control $(9.55 \pm 0.07 \mathrm{~g})$ they stood in second, third and fourth positions respectively.

Fig.1 Growth of $L$. vannamei fed with different concentrations of garlic powder supplementation 


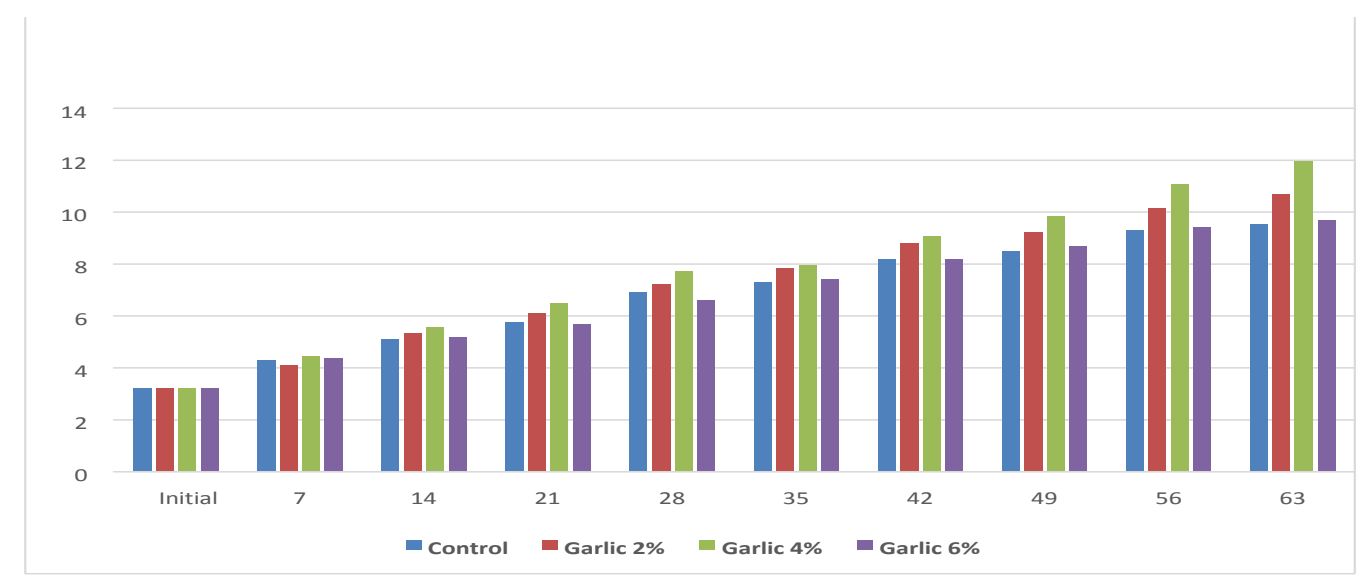

Fig.2 Growth of L. vannamei fed with different concentrations of ginger powder supplementation

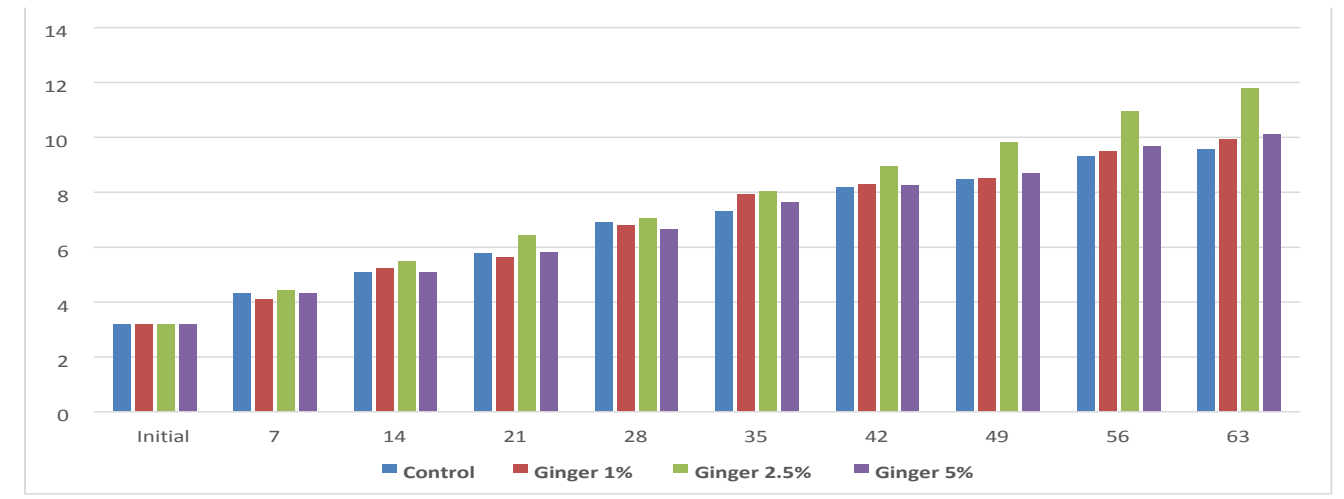

Fig.3 Growth of L. vannamei fed with different concentrations of fenugreek powder supplementation

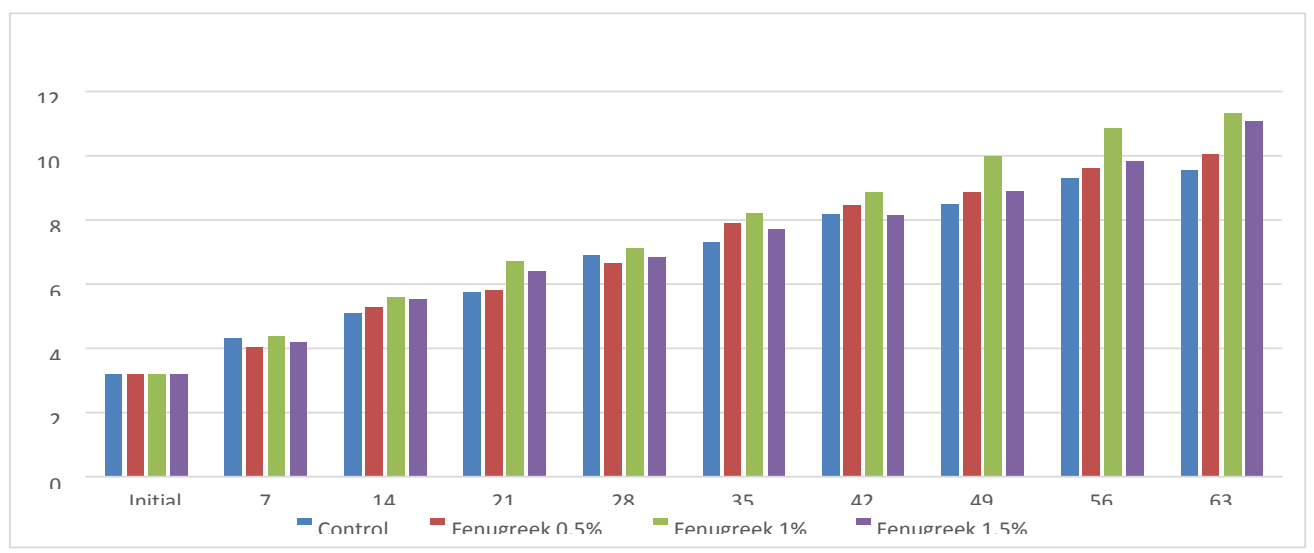

The growth data was subjected to analysis of variance (ANOVA) at $1 \%$ and $5 \%$ level of 
significance. The statistical analysis has shown that $\mathrm{F}$ - value is found to be significant among treatments. Since F- value is found to be significant, the pair wise comparison of any two Treatments could be done by computing RBD two-way classification. The Treatment FP $1 \%$ is found to be significantly superior when compare to other Treatments. Treatment FP 1\% has shown significantly different from all other Treatments. The second and third positions were occupied by FP $1.5 \%$ and FP $0.5 \%$ respectively. There was a significant difference between the culture periods also. Growth performance of $L$. vannamei fed with different concentration of fenugreek powder supplementation. The results in the present study were correlated with the earlier observations in $M$. rosenbergii (Poongodi et al., 2012), in Cyprinus carpio (Roohi et al., 2015). Growth stimulants, antioxidants, vitamins and minerals present in fenugreek may have contributed for the increase in weight gain of L. vannamei fed with herbal supplemented diets. Growth performance came to stand still or reduction from the 1\% FP inclusion level in the diet may be due to reduction in palatability of the feed.

\section{References}

Chang, Y., C. Liu, C. Wu, C. Chiang, J. Lian and S. Hsieh, 2012. Dietary administration of zingerone to enhance growth, non-specific immune response and resistance to Vibrio alginolyticus in Pacific white shrimp (Litopenaeus vannamei) juveniles. Fish and Shellfish Immunol., 32: 284290.

Chitarasu TK, Babu MM, Sekar RJR, Marian MP (2002) Developing Artemia enriched herbal diet for producing quality larvae in Penaeus monodon (Fabricius). Asian Fish Sci 15:21-32

Corzo-Martinez M, Corzo N, Mar Villamiel.
Biological properties of onions and garlic, Trends in Food Science \& Technology, 2007; 18:609-625.

Coutteau P., Ceulemans S., Halteren van Alexander: Botanical extracts improve productivity and economics in aquaculture, Nutrad International, Belgium, 2011.

Cowan, M. M. (1999). Clin. Microbiol. Rev., 12: 564.

El-Desouky, H., El-Asely, A., Shaheen, A.A. and Abbass, A., 2012. Effects of Zingiber officinalis and Cyanodondactylon on the growth performance and immune parameters of Macrobrachium rosenbergii, World Journal of Fish and Marine Sciences, 4(3): 301-307.

FAO. The State of World Fisheries and Aquaculture. FAO Fisheries and Aquaculture Department, Rome, Italy, 2014, 200.

Keshavanth, P. and Jayaram, K.E. (2000). Growth Response of the Giant Freshwater Prawn, Macrobrachium rosenbergii to Feed Additive, Nutripro-aqua. The 5th Asian Fisheries Forum, Book of Abstracts, Fisheries and Food Security Beyond the Year 2000, Bangkok, Thailand.

Labrador, Recamar C. Guinares and Gaily jubie S. Hontiveros effect of garlic powder supplementation diets on the growth and survival of pacific white leg shrimp (Litopenaeus vannamei), Animal husbandry and veterinary science research article.

Levic J, Sinisa M, Djuragic O, Slavica S. Herbs and organic acids as an alternative for antibiotic- growthpromoters. Archiva Zootechnica. 2008; 11:5-11.

Penaflorida, V.D. (1995) Effect of papaya leaf meal on the Penaeus monodon post larvae, Israeli. J. Aquac. Bamidgeh, 47, 25-33. 
Platel, K. and K. Srinivasan, 2000. Influence of dietary spices and their active principles on pancreatic digestive enzymes in albino rats. Nahrung, 44: $42-6$.

Poongodi, R., Saravanabhavan, P., Muralisankar, T., and Radhakrishnan, S. (2012). Growth promoting potential of garlic, ginger, turmeric and fenugreek on the freshwater prawn Macrobrachium rosenbergii. International Journal of Pharma and Bio Sciences, 3, 914-926.

RahimiYadkoori, Nasrin; Zanguee, Nasim Mousavi, Seyed Mohammad*; Zakeri, Mohammad Effects of Ginger (Zingiber officinale) Extract on Digestive Enzymes and Liver Activity of Mesopotamichthys sharpeyi Fingerlings Journal of the Persian Gulf
(Marine Science)/Vol. 6/No. 19/March 2015/10/1-10.

Rebecca, A.A. and P.S. Bhavan, 2011. Growth performance of Macrobrachium rosenbergii post larvae fed with vegetable wastes and palmolein supplemented formulated feeds. Rec. Res. Sci. Tech., 3: 69-76.

Shetty, K. (1997). Asia. Pac. J. Clin. Nutr., 21 (1997) 79.

Sivam G.P. Recent advances on the nutritional effects associated with the use of garlic as supplement. Am. Soc. Nutr. Sci, 2001, 1106-8.

Venkataramalingam, K., Godwin, C.J. and Citarasu T. (2007). Zingiber officinalis, an herbal appetizer in the tiger shrimp Penaeus monodon (Fabricius) larviculture. Aquaculture Nutrition 13 (6): 439-443.

\section{How to cite this article:}

Mahesh Kumar, R., A. Chandra Sekhara Rao, Narshivudu Daggula, Ganesh Guguloth, B. Yesu Das and Ashok indhuri. 2019. Growth Promoter Effect of Ginger, Garlic and Fenugreek on Pacific White Leg Shrimp (Litopenaeus vannamei). Int.J.Curr.Microbiol.App.Sci. 8(02): 29933001. doi: https://doi.org/10.20546/ijcmas.2019.802.349 